\title{
The Economics of US-style Contingent Fees and UK-style Conditional Fees
}

\author{
Winand Emons \\ Nuno Garoupa
}

04-07

May 2004

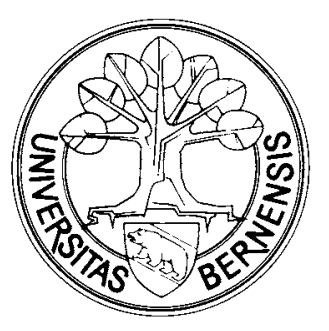

Universität Bern

Volkswirtschaftliches Institut

Gesellschaftstrasse 49

3012 Bern, Switzerland

Tel: 41 (0)316314506

Web: www.vwi.unibe.ch 


\title{
The Economics of US-style Contingent Fees and UK-style Conditional Fees*
}

\author{
Winand EMONS ${ }^{\dagger}$ \\ Universität Bern \\ CEPR
}

\author{
Nuno GAROUPA \\ Universidade Nova de Lisboa \\ CEPR
}

May 2004

\begin{abstract}
Under contingent fees the attorney gets a share of the judgement; under conditional fees the lawyer gets an upscale premium if the case is won which is, however, unrelated to the adjudicated amount. We compare conditional and contingent fees in a principal-agent framework where the lawyer chooses unobservable effort after she has observed the amount at stake. Contingent fees provide better incentives than conditional fees independently of whether upfront payments are restricted to be non-negative or not. Under contingent fees the attorney uses her information about what is at stake more efficiently.
\end{abstract}

Keywords: contingent fees, conditional fees, moral hazard, incentives JEL: D82, K1

*We thank Alon Klement, Gerd Mühlheusser, Zvika Neeman, and Ralph Siebert for helpful comments. Garoupa acknowledges financial support by Nova Forum and FCT, POCTI/ECO/44146/2002. Emons acknowledges the hospitality of the department of economics at Purdue University. The usual disclaimers apply.

$\dagger$ Abteilung für Wirtschaftstheorie, Volkswirtschaftliches Institut, Universität Bern, Gesellschaftsstrasse 49, CH-3012 Bern, Switzerland. Phone: +43-31-6313922. Fax: +4131-6313992. Email: winand.emons@vwi.unibe.ch

${ }_{\ddagger}^{\ddagger}$ Faculdade de Economia, Universidade Nova de Lisboa, Campus de Campolide, P1099-032 Lisboa, Portugal. Phone: 351-21-3801600. Fax: 351-21-3870933. Email: ngaroupa@fe.unl.pt 


\section{Introduction}

In a typical tort case in the United States the plaintiff's attorney receives her compensation in form of a contingent fee. Under this payment scheme the attorney gets a share of the judgements if her client wins and nothing if her client loses. A common practice is to use a sliding scale: the attorney gets one-third if the case is settled without trial, $40 \%$ if the plaintiff wins at trial, and $50 \%$ if a judgement for the plaintiff is affirmed on appeal.

The use of contingent legal fees is by now widespread in the US. In a wellknown empirical study, Kritzer (1990) presents suggestive data. He observes that individual litigants tend to use contingent fees, and they are mostly used in torts (more than 87\%) and contracts (around 53\%), whereas hourly fees are essentially used in divorce and other domestic issues. These figures have been confirmed and discussed in later studies by Kritzer (2002) himself as well as by Brickman (2003a, 2003b).

In Europe the picture is quite different. Contingent legal fees are strictly forbidden (pactum cuota litis is not allowed by the ethical code of the European association of lawyers), albeit evidence that in some countries they have been unofficial practice. Nevertheless, market pressure has led some countries to allow conditional fees. Under conditional fees the lawyer gets an upscale premium if the case is won. This premium is not related to the amount adjudicated. The United Kingdom started introducing conditional fees in the nineties ${ }^{1}$, followed by Belgium and the Netherlands, the latter now considering to formally allow contingent fees. Spain, France, Italy, and Portugal are considering the introduction of conditional fees. Germany has also relaxed some restrictions by means of third party contingent contracts, though not to the extreme of accepting conditional fees (Kirstein and Rickman, 2004).

We may say that the type of contract for legal fees has been changing rapidly all over Europe, clearly following the US tendency, but still not to

\footnotetext{
${ }^{1}$ More precisely, in 1997, the Scottish model of speculative actions, where a lawyer receives the normal fee only when successful, was extended to England and Wales with a provision that a lawyer can charge an extra percentage of those fees to reflect the risk of not being paid. Before 1997, conditional fees were used in personal injury, insolvency and cases to the European Court of Human Rights only, and in 1997 were extended to most civil cases (Yarrow, 2001).
} 
the point of allowing contingent fees. We should not, however, neglect that contingent as well as conditional fees have raised some antagonism among legal scholars (See, 1984; Kurzlik, 1999; Kritzer, 2002; Zander, 2002; Brickman 2003a, 2003b), including the ongoing controversies among economists over contingent legal fees creating too much litigation and the question of allocation of settlement rights (Miller, 1987; Miceli and Segerson, 1991; Thomason, 1991; Rickman, 1994; Segerson, 1994; Hay, 1997; Hadfield, 2000; Polinsky and Rubinfeld, 2002; Choi, 2003).

Both, contingent as well as conditional fees, pay for performance by compensating the lawyer by a higher fee if the case is won. The main difference between contingent and conditional fees is that the former pays a percentage of the judgement whereas the latter pays an upscale premium not related to the adjudicated amount.

Previous literature, which we describe at the end of the Introduction, has mostly addressed the use of contingent legal fees in the US, but has ignored the possibility of conditional legal fees. As far as we know, this -together with a companion paper (Emons 2004)- are the first attempts to provide an efficiency-comparison between US-style contingent and UK-style conditional fees. Here we consider the following simple principal-agent set-up. A client hires a lawyer. After they have signed the contract, the lawyer learns the amount of adjudication if the case is won. Then the lawyer strategically decides how much effort she puts into the case: the more effort, the higher the probability of winning the case. Effort is not observed by the client. If, e.g., the lawyer were paid a fixed fee, she would provide no effort.

We find that both, contingent and conditional fees, give the lawyer an incentive to provide effort. Under conditional fees the upscale payment is not related to the adjudicated amount. Therefore, the lawyer's effort does not depend on the amount at stake. Under contingent fees the attorney gets a fraction of the judgment. She adjusts effort to the adjudicated amount: the higher the judgment, the more effort she puts into the case. Accordingly, under contingent fees the attorney uses her information about the amount at stake whereas under conditional fees she does not. Therefore, contingent fees are more efficient than conditional fees. This holds true independently of upfront payments to the lawyer being restricted to be non-negative or not.

Then we extend the model to the problem that under contingent but 
not under conditional fees the lawyer may have an incentive to drop the case once she learned the amount at stake. If upfront payments are non-restricted, the client gains from the option of dropping the case; when upfront fees are restricted to be non-negative, the lawyer gains and the client loses.

Previous literature has addressed the use of contingent legal fees in the US, but has overlooked the possibility of conditional legal fees. Contingent fees may be seen as a mechanism to finance cases when the plaintiff is liquidity constrained and capital markets are imperfect (Posner 1986, 534-540). This observation relies on the fact that many plaintiffs do not have enough assets to hire an attorney under a regime of hourly fees, a problem also emphasized by those who oppose the substitution of legal aid by conditional fees in Europe (White, 1978; Yarrow, 2001).

A second explanation sees contingent fees as a risk-sharing device (Posner 1986, 534-540). The lawyer is presumably less risk averse than the client due to the fact that it is easier for her to diversify the risks from lawsuits. Thus, contingent legal fees would share the risk more efficiently than hourly or flat fees because they shift some of the risk from the more risk averse client to the less risk averse lawyer. Another explanation is related to the use of contingent legal fees in class-action litigation (Lynk, 1990, Klement and Neeman, 2004) and third-party involvement in litigation, such as insurance companies (Kirstein and Rickman, 2004).

The other explanations for contingent fees are all based on asymmetric information between the lawyer and her client. Contingent fees can be used to address a moral hazard problem: If the client cannot observe the attorney's effort, then tying the attorney's fees to the trial's outcome provides better incentives to exert efficient effort than hourly fees which tend to induce shirking (Schwartz and Mitchell, 1970; Mitchell and Schwartz, 1972; Danzon, 1983; Halpern and Turnbull, 1983; Swanson, 1991; Gravelle and Waterson, 1993, Polinsky and Rubinfeld, 2003).

Rubinfeld and Scotchmer (1993) suppose that the attorney has better information about her ability and the plaintiff has better information about the merits of his case. A client who has a high-quality case will be willing to pay a high fixed fee and a low contingency percentage, while a client with a low-quality case will prefer a low fixed fee and a high contingency percentage. In contrast, a high-quality attorney will signal her ability by working for a 
high contingency percentage.

Dana and Spier (1993) and Emons (2000) look at the role of the attorney as an expert. Clients do not know the merits of their case. The attorney as the expert finds out about these merits. In Dana and Spier (1993) the lawyer recommends whether to pursue or to drop the case; they conclude the optimal compensation scheme will pay the attorney a share of the plaintiff's award. In Emons (2000) the attorney recommends how much work to put into the case; he finds that paying the attorney by the hour is generally better than using contingent fees.

The economic literature on conditional fees is essentially UK-based (Maclean and Rickman, 1999; Yarrow, 2001; Fenn et. al, 2004) and has been concerned with the impact on the outcome of legal cases and the effects on the demand and supply of legal aid.

Emons (2004) compares conditional and contingent fees in a framework where lawyers are uninformed about the clients' cases. Payments to the lawyer are restricted to be non-negative. Moral hazard by lawyers rules out fixed wage components. If there is asymmetric information about the merits of cases, in equilibrium attorneys will offer only conditional fees. If there is asymmetric information about the risk of cases, only contingent fee contracts are offered in equilibrium.

In the next section we describe the model and derive our results. Section 3 concludes.

\section{The model}

A plaintiff has been a victim of an accident or a breach of contract. He sues the defendant to be paid damages $J$. With the purpose of being compensated, he hires a lawyer. The probability of winning $p$ depends on the unobservable costly effort $e \in[0,1]$ exerted by the lawyer. More specifically, let $p(e)=$ $e^{\gamma}, \gamma \in(0,1){ }^{2}$ We thus assume $p(0)=0, p(1)=1, p_{e}>0, p_{e e}<0$, and $p_{e}(0)="+\infty "$. Effort increases the probability of prevailing, but at a decreasing rate. The lower $\gamma$, the higher the marginal productivity of effort

\footnotetext{
${ }^{2}$ We work with this fairly general class of functions to have closed form solutions for our welfare comparisons.
} 
for low levels of effort, and vice versa for high values of $\gamma$. For simplicity, the attorney's cost of effort is $e$.

When the case is won, the plaintiff gets $J$ from the defendant whereas he gets nothing when the case is lost. The amount of adjudication $J$ is the realization of a random variable with support $[0,1]$, c.d.F. $G$, and expected value $E(J) \in(0,1)$.

The timing of events is as follows. When the plaintiff and the attorney sign the contract, they know the set-up we have just described. Neither party knows the realization $J$. After the lawyer has accepted the contract, she learns the realization $J$. Then she decides strategically on effort $e$; effort is not observed by the plaintiff. The case is then won with probability $p(e)$ or lost with probability $(1-p(e))$ and payoffs are realized.

We study two possible fee contracts between the plaintiff and the attorney:

Definition 1 A contingent fee contract $S$ is described by a fixed component $w$ plus a percentage $\alpha$ of the adjudicated amount $J$ if the case is won. The lawyer gets $w$ if she loses and $w+\alpha J$ if she wins. Formally,

$$
S= \begin{cases}w+\alpha J, & \text { if the case is won; } \\ w, & \text { if the case is lost. }\end{cases}
$$

Definition 2 A conditional fee contract $K$ is given by a fixed component $w$ plus a upscale fee $d$ not related to the adjudicated amount $J$ if the case is won. The attorney gets $w$ if she loses and $w+d$ if she wins. Formally,

$$
K= \begin{cases}w+d, & \text { if the case is won; } \\ w, & \text { if the case is lost. }\end{cases}
$$

The purpose of our principal-agent model is to analyze contingent and conditional fees in solving the moral hazard problem created by the unobservability of the lawyer's effort. A flat fee clearly does not align the interests of the attorney with those of the plaintiff: under a flat fee the lawyer chooses $e=0$. Both, contingent and conditional fee contracts may mitigate moral hazard, but not necessarily efficiently so.

Immediately we can think that the fixed component of the contract $w$ is an upfront flat fee and should be used to solve the participation constraint; the contingent component $(\alpha J)$ and the conditional component $(d)$ are the variable part of the contract that could be used to solve the incentive compatibility constraint. Let us now make these ideas more precise. 
Given $J$, the expected utility of the risk neutral attorney under contingent fees is:

$$
V_{S}(J)=p(e) \alpha J-e+w .
$$

The lawyer gets the fixed component $w$ and exerts effort $e$ in any case. With probability $p(e)$ the case is won and the adjudicated amount is $J$ of which the attorney gets the fraction $\alpha$. Given $J$, the expected utility of the risk neutral plaintiff under contingent fees is:

$$
U_{S}(J)=p(e)(1-\alpha) J-w .
$$

The plaintiff gets the fraction $(1-\alpha)$ of $J$ and has to pay the fixed component $w$ independently of the outcome of the trial. The ex ante expected utilities of the plaintiff and the lawyer are

$$
\begin{aligned}
& E\left(U_{S}\right)=E(p(e)(1-\alpha) J)-w \\
& E\left(V_{S}\right)=E(p(e) \alpha J-e)+w .
\end{aligned}
$$

Given $J$, under conditional fees the expected utility of the attorney is :

$$
V_{K}(J)=p(e) d-e+w .
$$

If the case is won, the lawyer gets the additional $d$, independently of the adjudicated amount $J$. Given $J$, the expected utility of the plaintiff under conditional fees is

$$
U_{K}(J)=p(e)(J-d)-w .
$$

The ex ante expected utility of the plaintiff and the attorney are

$$
\begin{aligned}
& E\left(U_{K}\right)=E(p(e)(J-d))-w, \\
& E\left(V_{K}\right)=E(p(e) d-e)+w .
\end{aligned}
$$

Note that the ex post efficient level of effort exerted by the lawyer satisfies $p_{e} J=1$ or in closed form $e^{*}(J)=(\gamma J)^{1 /(1-\gamma)}$. The efficient level of effort thus increases with $J$ : the more merit the case has, the higher should be the attorney's effort. ${ }^{3}$

\footnotetext{
${ }^{3}$ We measure welfare by the expected judgment minus the cost of effort, so that the lawyer's effort is socially valuable. Litigation is sometimes also seen as a pure rent seeking game where resources are wasted for purely distributional purpose. See Shavell (1997) for the fundamental divergence between the private and the social motive to litigate.
} 
Assume that the plaintiff's reservation utility is zero and the lawyer's is $v \in[0, E(J))$. Note that lawsuits with $p\left(e^{*}(J)\right) J-e^{*}(J)<v$ should be dropped since the expected value of the lawsuit is less than the opportunity cost.

\section{$2.1 \quad$ Perfect information}

As points of reference, let us briefly consider the cases of perfect and of imperfect but symmetric information concerning $J$. If both parties know the realization of $J$ at the time of contracting, contingent and conditional fee contracts are equivalent. Any $d=\alpha J$ will produce the same type of incentives for the attorney to exert effort and the same risk allocation; the only risk is losing the case which is the same for both types of contracts.

\subsection{Imperfect but symmetric information}

Suppose neither lawyer nor plaintiff know the realization of $J$ at the time the attorney chooses $e$; both only know the expected value of adjudication to be $E(J)$. The two regimes are equivalent in solving the misalignment of objectives. Any $d=\alpha E(J)$ generates the same type of incentive for exerting effort as contingent fees.

Nevertheless, the two regimes give rise to different risk allocations. Contingent fees are more risky than conditional fees for the lawyer, the opposite is true for the client.

Suppose the attorney is risk neutral and the plaintiff is risk averse. This is typically true in the personal segment of the market for legal services but not in the corporate segment. Then a contingent fee contract is more efficient than a conditional fee contract: both are equally efficient in solving the incentive problem, but the former is better in achieving efficient risksharing than the latter. The opposite result will hold if lawyer is more risk averse than plaintiff.

\subsection{Imperfect and asymmetric information}

Let us now return to the situation where the lawyer knows $J$ at the time of choosing effort but not the plaintiff. Under contingent fees the attorney 
maximizes $V_{S}$ with respect to $e$. The choice of effort will satisfy $p_{e} \alpha J=$ 1 or in closed form $\hat{e}_{S}=(\gamma \alpha J)^{1 /(1-\gamma)}$. Under conditional fees the lawyer maximizes $V_{K}$; here optimal effort satisfies $p_{e} d=1$ or $\hat{e}_{K}=(\gamma d)^{1 /(1-\gamma)}$. Under contingent fees effort $e$ varies with $J$; under conditional fees effort is deterministic and independent of $J$.

\subsubsection{Optimal Contracts with no restriction on upfront payments}

The fixed upfront component of the salary solves the participation constraint as in the principal-agent literature. Therefore, for contingent fee contracts

$$
w=v-\alpha \int_{J}\left(p\left(\hat{e}_{S}\right) J-\hat{e}_{S}\right) d G(J)
$$

and for conditional fee contracts

$$
w=v-\left(p\left(\hat{e}_{K}\right) d-\hat{e}_{K}\right)
$$

Note that the lawyer agrees to the contract without knowing $J$. That is, in both cases the fixed part of the contract is deterministic and independent of $J$. For the time being, we assume that there is no restriction of the type $w \geq 0$, an assumption relaxed later due to the champerty doctrine in the US and forbidden pactum cuota litis in Europe.

A risk neutral plaintiff has the following expected payoffs after solving the participation constraint:

$$
\left.E\left(U_{S}\right)=\int_{J}\left[p\left(\hat{e}_{S}\right) J-\hat{e}_{S}\right)\right] d G(J)-v
$$

if a contingent fee contract is agreed upon, and

$$
E\left(U_{K}\right)=p\left(\hat{e}_{K}\right) E(J)-\hat{e}_{K}-v
$$

if the fee is conditional. The plaintiff chooses the contingent fee $\alpha$ and the conditional fee $d$ so as to maximize $E\left(U_{S}\right)$ and $E\left(U_{K}\right)$.

It follows immediately that the optimal choice of fee is $\alpha=1$ and $d=$ $E(J)$. The rationale for the first result is that the attorney becomes the residual claimant of the amount adjudicated: there is no problem of risk sharing, but a high-powered incentive contract is needed to solve the moral hazard problem. With a conditional fee it is impossible to make the choice 
of effort depend on $J$. Taking the average $J$ as conditional fee implements the average effort level.

By construction, contingent fees are necessarily more efficient than conditional fees in maximizing the surplus of the contract. The lawyer's effort maximizing total surplus satisfies $p_{e} J=1$. Under contingent fees this is feasible if $\alpha=1$. However, under conditional fees, this is not possible because the upscale fee is not related to the adjudicated amount and has to be contracted before the plaintiff knows the exact value of $J$.

In terms of our example under a regime of conditional fees the problem for the client is to choose $d$ so as to maximize $E\left(p\left(\hat{e}_{K}\right) J-\hat{e}_{K}\right)-v$. The optimal solution is $d=E(J)$ and the expected payoff for the plaintiff is

$$
E\left(U_{K}\right)=(1-\gamma) \gamma^{\gamma /(1-\gamma)} E(J)^{1 /(1-\gamma)}-v
$$

Under a regime of contingent fees the problem for the plaintiff is to choose $\alpha$ so as to maximize $E\left(p\left(\hat{e}_{S}\right) J-\hat{e}_{S}\right)-v$. Therefore, $\alpha=1$ and the expected payoff for the plaintiff is

$$
E\left(U_{S}\right)=(1-\gamma) \gamma^{\gamma /(1-\gamma)} E\left(J^{1 /(1-\gamma)}\right)-v
$$

Since $J^{1 /(1-\gamma)}$ is strictly convex, Jensen's inequality implies $E\left(J^{1 /(1-\gamma)}\right)>$ $E(J)^{1 /(1-\gamma)}$. Accordingly, contingent fees are always better than conditional fees. The principal's payoff is higher whereas the agent's payoff equals $v$ under both regimes. The intuition for the result is that the contingent fee contract allows the attorney to use her informational advantage, which benefits the plaintiff after the appropriate choice of the fixed salary. Notice that the plaintiff chooses contingent and conditional fees to maximize the joint surplus of the contract (since the participation constraint is solved in equality for the attorney).

Finally, we need to check the participation constraint for the plaintiff; the lawyer's participation constrained is satisfied by construction. The plaintiff's participation constraint is satisfied for both types of fee contracts as long as

$$
E\left(U_{K}\right) \geq 0 \Leftrightarrow v \leq(1-\gamma) \gamma^{\gamma /(1-\gamma)} E(J)^{1 /(1-\gamma)}
$$

It will be not satisfied for both types if

$$
v>(1-\gamma) \gamma^{\gamma /(1-\gamma)} E\left(J^{1 /(1-\gamma)}\right)
$$


For intermediate values,

$$
E(J)^{1 /(1-\gamma)}<v /(1-\gamma) \gamma^{\gamma /(1-\gamma)} \leq E\left(J^{1 /(1-\gamma)}\right)
$$

the participation constraint is satisfied for the contingent fee contract but not for the conditional fee contract. Low valued lawsuits will not be taken to court at all and high valued lawsuits will be taken under conditional as well as under contingent fee contracts. For lawsuits valued in between, they will be taken only under contingent fee but not under conditional fee contract.

We summarize the preceding observations by the following Proposition.

Proposition 1 With no restrictions on upfront payments the optimal contingent fee contract entails $\alpha=1$, implementing efficient effort. The attorney buys the case from the client at a price $\left(-w_{S}\right)>0$ which puts her on her reservation utility $v$.

The optimal conditional fee contract entails $d=E(J)$, implementing an inefficient average effort level. The lawyer buys the case from the client at a price $\left(-w_{K}\right)>0$ which puts her on her reservation utility $v$.

Whereas the lawyer is indifferent between the two regimes, the client strictly prefers contingent fees.

\subsubsection{Optimal Contracts with non-negative upfront payments}

Consider now the scenario where a constraint $w \geq 0$ exists. Without this constraint we have solved the problem by finding a fixed salary that solves the participation constraint with equality when $\alpha=1$ and $d=E(J)$ for contingent and conditional fee contracts respectively. Therefore, the fixed salary is negative. The attorney effectively buys the case from the plaintiff and if we impose $w \geq 0$ this constraint actually binds for both regimes.

We solve the problem for the plaintiff when $w$ is zero so that both contingent and conditional fee contracts only have variable components. ${ }^{4} \mathrm{We}$ first ignore the lawyer's participation constraint. Under conditional fees, the

\footnotetext{
${ }^{4}$ Note that with $w=0$ contingent and conditional fees generate the same payoff structure as equity finance and a standard debt contract. If $w>0$, conditional fess resemble a debt contract with a collateral; see Emons (2004).
} 
plaintiff now maximizes $p\left(\hat{e}_{K}\right)(E(J)-d)$. The optimal solution is $d=\gamma E(J)$. The expected payoff for the client is

$$
E\left(U_{K}\right)=(1-\gamma) \gamma^{2 \gamma /(1-\gamma)} E(J)^{1 /(1-\gamma)}
$$

whereas the attorney get $E\left(V_{K}\right)=\gamma E\left(U_{K}\right)$.

Under a regime of contingent fees, the client maximizes $E\left((1-\alpha) p\left(\hat{e}_{S}\right) J\right)$. The optimal solution is $\alpha=\gamma$ and the expected payoff for the client is

$$
E\left(U_{S}\right)=(1-\gamma) \gamma^{2 \gamma /(1-\gamma)} E\left(J^{1 /(1-\gamma)}\right)
$$

The attorney get $E\left(V_{S}\right)=\gamma E\left(U_{S}\right) .^{5}$

Note that plaintiff and lawyer do better under contingent fees because $E\left(J^{1 /(1-\gamma)}\right)>E(J)^{1 /(1-\gamma)}$. Under contingent fees the attorney uses the information she has about $J$ when choosing effort whereas under conditional fees she does not.

First note that the plaintiff's participation constraint is always satisfied. Next we need to check that the participation constraint for the lawyer is satisfied in both cases. That is the case as long as $E\left(V_{K}\right) \geq v$. Let us assume that this condition is satisfied with strict inequality in order not to solve the model with a binding lawyer's participation constraint. ${ }^{6}$

Under both contracts the attorney obviously does better in the second scenario with $w=0$ than in first scenario without this restriction where he gets exactly her reservation utility $v$. For the plaintiff the opposite is true. Under both contracts the joint surplus is smaller in the second scenario than in the first one; the lawyer gets more. Accordingly, the plaintiff's expected surplus is less if $w=0$ than if we allow for negative upfront payments. This is a standard result for second-best contracts. Effort is distorted downwards because the principal faces the trade-off of reducing the agent's rent versus providing incentives. To summarize:

\footnotetext{
${ }^{5}$ The higher is $\gamma$, the more high-powered are the incentive schemes under both set of fees and the higher the lawyer's share of the surplus. To achieve the same level of $p, e$ has to be higher the higher $\gamma$. Accordingly, incentives have to be stronger the higher $\gamma$.

${ }^{6}$ If the participation constraint binds, the optimal $\alpha>\gamma$ and $d>\gamma E(J)$ so as to guarantee $v$ for the attorney. Effort will go up, but the client will do worse because his share is lower.
} 
Proposition 2 Suppose $E\left(V_{K}\right)>v$. If $w \geq 0$, the optimal contingent fee contract entails $\alpha=\gamma$, implementing inefficiently low effort. The lawyer does better than his reservation utility $v$.

The optimal conditional fee contract entails $d=\gamma E(J)$, implementing an inefficient average effort level. The attorney does better than $v$.

Both, client and lawyer, strictly prefer contingent to conditional fees. Whereas the attorney is better off with the restriction $w \geq 0$, the opposite holds true for the client.

Notice however that the superiority of contingent fees in terms of efficiency has been obtained under the assumption that both players are risk neutral. Once we allow for the possibility that the plaintiff is less risk averse than the attorney, the result we have obtained does not necessarily hold. In the opposite case, our result is of course reinforced.

\subsection{Imperfect and asymmetric information when the lawyer can drop the case}

In the previous section we have assumed that the participation constraint is solved before the attorney learns the realization $J$. Once $J$ is revealed, the lawyer is stuck with the contract and she can only adjust her effort. The attorney cannot drop the case. Yet, under contingent fees if $J$ is small, the lawyer prefers to drop the case and earn $v$ with the outside opportunity to investing $\hat{e}_{S}$ and earn the (miserable) $p\left(\hat{e}_{S}\right) \alpha J-\hat{e}_{S}$.

To be more precise, we assume that the lawyer can drop the case at zero cost once she discovers the true value of $J$ and before effort is chosen. The rule of "no damages" thus applies.

First note that under conditional fees the attorney has no incentive to drop the case because her payoff $p\left(\hat{e}_{K}\right) d-\hat{e}_{k}$ is independent of $J$.

Now consider contingent fees. The first scenario where the lawyer buys the case from the client is simple. Once the attorney learns that she better works elsewhere, she simply drops the case; her payment of $w$ is sunk at the time. This new option makes working on the case more attractive for the lawyer. If $J$ is low, she turns to her alternative job and gets $v$. This in turn allows the client to increase the price $\left(-w_{S}\right)$ the lawyer has to pay for the 
case. The attorney is indifferent as to whether she can drop the case or not; the client strictly prefers the latter option.

Next consider the second scenario with $w=0$. If $p\left(\hat{e}_{S}\right) \alpha J-\hat{e}_{S}<v$, the lawyer drops the case and earns $v$ elsewhere. Define $\hat{J}$ to satisfy $p\left(\hat{e}_{S}(\hat{J})\right) \alpha \hat{J}-$ $\hat{e}_{S}(\hat{J})=v$. In terms of the example $\hat{J}=(v /(1-\gamma))^{(1-\gamma)} 1 /\left(\alpha \gamma^{\gamma}\right)$. Accordingly, for $J \geq \hat{J}$ the attorney performs and for $J<\hat{J}$ she drops the case.

The lawyer's expected utility is

$$
E\left(V_{S}\right)=v \int_{0}^{\hat{J}} d G(J)+\int_{\hat{J}}^{1}\left[p\left(\hat{e}_{S}\right) \alpha J-\hat{e}_{S}\right] d G(J)>v .
$$

The plaintiff's expected utility is

$$
E\left(U_{S}\right)=\int_{\hat{J}}^{1}\left[p\left(\hat{e}_{S}\right)(1-\alpha) J\right] d G(J) .
$$

Increasing $\alpha$ now has two effects on the lawyer's behavior: As in the preceding scenario it increases the attorney's effort. Moreover, now we have the additional effect that increasing $\alpha$ increases the performance set $[\hat{J}, 1]$. Raising $\alpha$ lowers $\hat{J}$, the judgement rendering the lawyer indifferent between pursuing and dropping the contract. Consequently, the optimal $\alpha$ will exceed $\gamma$, the optimal value if the lawyer cannot drop the case. We may, therefore, conclude that the option of dropping the case makes the attorney certainly better off: whenever $J$ is low, she turns to the outside job; when $J$ is high, she earns more on the case because $\alpha$ is higher. The client is certainly worse off. When $J$ is low, he gets nothing because the case is dropped. When stakes are high he gets a lower share.

When the attorney can drop the case, the joint surplus is higher under contingent than under conditional fees: under contingent fees the lawyer uses this option whereas under conditional fees she does not. The lawyer is better off under contingent fees. Whether the client does better under contingent than under conditional fees cannot be answered without specifying the c.d.F. $G$. 


\section{Conclusions}

In this paper we have analyzed UK-style conditional and US-style contingent fees with respect to the incentives they give the attorney to work hard. Under contingent fees the attorney's effort is tied to the amount at stake; under conditional fees the effort choice is independent of the judgment. Because the attorney effectively uses her information about the adjudicated amount, contingent fees are more efficient than conditional fees. This holds true if upfront payments to the lawyer are restricted to be non-negative or not. To put it differently: Looking at incentives, contingent fees are clearly better because the agent with more information becomes residual claimant.

Conditional fees lead to more efficient risk-sharing if the plaintiff is less risk averse than the lawyer. This seems to be true in the corporate segment of the market for legal services, essentially contract and property litigation. This seems not be the case in the personal segment of the market, that is, personal injury litigation. Thus, for the personal segment we may conclude that contingent fees are better for incentives and for risk sharing. However, in the corporate segment conditional fees could be better than contingent fees because the superior risk-allocation may outweigh the inferior incentives.

Our model suggests that conditional fees could do also better than hourly and flat fees in the corporate market by providing a compromise between risksharing and incentives, saving on the need for in-house counsel to monitor external lawyers and reduce moral hazard. Such a result seems to be supported by the observation that in the US many large law firms do operate on the basis of flat fee plus bonus for performance, rather than contingent legal fees (Kritzer, 1990).

Our conjectures, if correct, also indicate that if at some point contingent legal fees are allowed for in Europe, they would replace conditional fees in personal litigation if providing incentives is the main issue. If, however, asymmetric information about the merits of cases is the major problem, conditional fees will be preferred over contingent fees (Emons 2004). Hopefully, the possible introduction of contingent legal fees in the Netherlands will provide the natural experiment. 


\section{References}

BrickMAN , L. Effective Hourly Rates of Contingency Fee Lawyers: Competing Data and Non-Competitive Fees, Washington University Law Quarterly 81 (2003a): 653-736.

Brickman, L. The Market for Contingent Fee-Financed Tort Litigation: Is it Price Competitive?, Cardozo Law Review 25 (2003b): 65-128.

Chor, A. Allocating Settlement Authority under a Contingent-Fee Arrangement, Journal of Legal Studies 32 (2003): 585-610.

DANA, J. AND K. SpIER. Expertise and Contingent Fees: the Role of Asymmetric Information in Attorney Compensation, Journal of Law, Economics and Organization 9 (1993): 349-367.

DAnzon, P. Contingent Fees for Personal Injury Litigation, Bell Journal of Economics 14 (1983): 213-224.

Emons, W. Expertise, Contingent Fees, and Insufficient Attorney Effort, International Review of Law and Economics 20 (2000): 21-33.

Emons, W. Conditional versus Contingent Fees, Discussion Paper May (2004).

Fenn, P., A. Gray, N. Rickman, and H. Carrier, The Impact of Conditional Fees on the Outcome of Personal Injury Cases, Journal of Insurance Research and Practice (2004): Forthcoming.

Gravelle, H. And M. Waterson. No Win, No Fee: Some Economics of Contingent Legal Fees, Economic Journal 420 (1993): 1205-1220.

Hadfield, G. K. The Price of Law: How the Market for Lawyers Distorts the Justice System, Michigan Law Review 98 (2000): 953-1006.

Halpern, P. J. And S. M. Turnbull. Legal Fees Contracts and Alternative Cost Rules: An Economic Analysis, International Review of Law and Economics 3 (1983): 3-26.

HAY, B. Contingent Fees and Agency Costs, Journal of Legal Studies 25 (1996): 503-533.

HAY, B. Optimal Contingent Fees in a World of Settlement, Journal of Legal Studies 26 (1997): 259-278.

Klement, A. And Z. Neeman. Incentive Structures for Class Action Lawyers, Journal of Law, Economics, and Organization (2004), 125-147.

Kirstein, R. And N. Rickman. Third Party Contingency Contracts in 
Settlements and Litigation, Journal of Institutional and Theoretical Economics (2004): Forthcoming.

Kritzer, H. The Justice Broker: Lawyers and Ordinary Litigation (1990). New York: Oxford University Press.

Kritzer, H. Seven Dogged Myths Concerning Contingency Fees, Washington University Law Quarterly 80 (2002): 739-785.

Kurzlik, P. Contingent Fees: The Ethical and Organisational Impact on the Bar, Modern Law Review 62 (1999): 850-878.

Lynk, W. J. The Courts and the Market: An Economic Analysis of Contingent Fees in Class-Action Litigation, Journal of Legal Studies 19 (1990): 247-260.

Maclean, M. and N. Rickman. No House, No Fee: Conditional Fees in Family Cases, Family Law 29 (1999): 245-248.

MiCEli, T. J. Do Contingent Fees Promote Excessive Litigation?, Journal of Legal Studies 23 (1994): 211-224.

Miceli, T. J. And K. Segerson. Contingent Fees for Lawyers: The Impact on Litigation and Accident Prevention, Journal of Legal Studies 20 (1991): 381-399.

Miller, G. P. Some Agency Problems in Settlement, Journal of Legal Studies 15 (1987): 189-215.

Mitchell, D. J. And M. L. Schwartz. Theoretical Implications of Contingent Legal Fees, Quarterly Review of Economics and Business 12(1972): 69-76.

Polinsky, A. M. And D. Rubinfeld. A Note on Settlements under the Contingent Fee Method of Compensating Lawyers, International Review of Law and Economics 22 (2002): 217-225.

Polinsky, A. M. And D. Rubinfeld. Aligning the Interests of Lawyers and Clients, American Law and Economics Review 5 (2003): 165-188.

Posner, R. Economic Analysis of Law, 3rd ed., Boston: Little Brown (1986).

Rickman, N. The Economics of Contingency Fees in Personal Injury Litigation, Oxford Review of Economic Policy 10(1994): 34-50.

Rickman, N. Contingent Fees and Litigation Settlement, International Review of Law and Economics 19 (1999): 295-31.

Rubinfeld, D. And S. Scotchmer. Contingent Fees for Attorneys: An 
Economic Analysis, Rand Journal of Economics 24 (1993): 343-356.

Santore, R. and A. D. Viard. Legal Fee Restrictions, Moral Hazard, and Attorney Rents, Journal of Law and Economics 44 (2001): 549-572.

Schwartz, M. L. And D. J. Mitchell. An Economic Analysis of the Contingent Fee in Personal Injury Litigation, Stanford Law Review 22 (1970): 1125-1162.

SeE, H. An Alternative to the Contingent Fee, Utah Law Review (1984): 485-509.

Shavell, S. The Fundamental Divergence between the Private and the Social Motive to Use the Legal System, Journal of Legal Studies 26 (1997): 575-612.

Swanson, T. M. The Importance of Contingent Fee Agreements, Oxford Journal of Legal Studies 11 (1991): 193-226.

Thomason, T. Are Attorneys Paid What They're Worth? Contingent Fees and the Settlement Process, Journal of Legal Studies 20 (1991): 187-223.

White, R. C. Contingent Fees: A Supplement of Legal Aid?, Modern Law Review 41 (1978): 286-298.

Yarrow, S. Conditional Fees, Hume Papers on Public Policy 8 (2001): $1-10$.

Zander, M. Where Are we Now on Conditional Fees? - Or Why This Emperor is Wearing Few, if Any, Clothes, Modern Law Review 65 (2002): 919-930. 